Grand Valley State University

ScholarWorks@GVSU

8-2011

\title{
Consumption of DHA + EPA by Low-Income Women During Pregnancy and Lactation
}

\author{
Carmen L. Nochera \\ Grand Valley State University, nocherac@gvsu.edu \\ Linda $\mathrm{H}$. Goossen \\ Grand Valley State University, goossenl@gvsu.edu \\ Annette R. Brutus \\ Kent County Health Department \\ Miranda Cristales \\ Grand Valley State University \\ Bethany Eastman \\ Grand Valley State University
}

Follow this and additional works at: https://scholarworks.gvsu.edu/bms_articles

Part of the Dietetics and Clinical Nutrition Commons

\section{ScholarWorks Citation}

Nochera, Carmen L.; Goossen, Linda H.; Brutus, Annette R.; Cristales, Miranda; and Eastman, Bethany, "Consumption of DHA + EPA by Low-Income Women During Pregnancy and Lactation" (2011). Peer Reviewed Articles. 2.

https://scholarworks.gvsu.edu/bms_articles/2

This Article is brought to you for free and open access by the Biomedical Sciences Department at ScholarWorks@GVSU. It has been accepted for inclusion in Peer Reviewed Articles by an authorized administrator of ScholarWorks@GVSU. For more information, please contact scholarworks@gvsu.edu. 


\title{
Consumption of DHA + EPA by Low-Income Women During Pregnancy and Lactation
}

\author{
Carmen L. Nochera, PhD, RD ${ }^{1}$; Linda H. Goossen, PhD, MT (ASCP) ${ }^{2}$; \\ Annette R. Brutus, RD ${ }^{3}$; Miranda Cristales, PA-C ${ }^{2}$; and \\ Bethany Eastman, PA-C ${ }^{2}$
}

Financial disclosure: none declared.

Background: The $\omega$-3-fatty acid docosahexaenoic acid (DHA) is important in infant brain development and maturation. The advisable intake of the $\omega-3$ fatty acids DHA and eicosapentaenoic acid (EPA) for pregnant and lactating women is $300 \mathrm{mg} / \mathrm{d}$ or $9 \mathrm{~g} /$ month. The objective of this cross-sectional study was to test the hypothesis that low-income pregnant/or lactating women do not consume advisable amounts of DHA+EPA and to determine whether any of the measured demographic factors were related to DHA and EPA consumption. Methods: This study was conducted September 2007 to March 2008 and used the N-3 Fatty Acid Food Frequency Questionnaire for dietary assessment in a convenience sample of women $(\mathrm{N}=68)$ enrolled in a local maternal infant health program. Women who reported fish or seafood allergies were excluded. The monthly consumption of DHA+EPA from food sources was measured, and participant race, ethnicity, country of origin, primary language, level of education, marital status, intake of prenatal vitamins containing DHA+EPA, and warnings of fish toxicity were assessed. The data were analyzed using 1-way analysis of variance and $t$ tests. Results: The average reported DHA+EPA intake was $1.18 \mathrm{~g} /$ month across all race/ethnicities. African Americans consumed significantly more DHA+EPA, $2.79 \mathrm{~g} /$ month, compared with Hispanics (1.64 g) and Caucasians $(0.93 \mathrm{~g})$. United States natives consumed significantly more DHA+EPA than immigrants $(2.45 \mathrm{~g}$ vs $1.55 \mathrm{~g})$. Conclusions: Low-income pregnant/and lactating women in the study consumed less than the advisable amounts of DHA+EPA. Both ethnicity and country of origin are related to DHA+EPA intake. (Nutr Clin Pract. 201 1;26:445-450)

Keywords: DHA; EPA; pregnancy; lactation; low-income women; fish consumption
B oth docosahexaenoic acid (DHA) and eicosapentaenoic acid (EPA) are $\omega-3$ fatty acids found in fish oil and are crucial in cellular processes that occur throughout human neurodevelopment. Docosahexaenoic acid has been indicated as an essential fatty acid in the development of the central nervous system, specifically in the myelination of axons within the central nervous system. ${ }^{1}$ Recent evidence suggests that women who regularly consume fish or fish oils during pregnancy and while breastfeeding may enhance their infant's vision, brain maturation, and developmental health. ${ }^{2-4}$ In addition to

From ${ }^{1}$ Department of Biomedical Sciences, College of Liberal Arts and Sciences, and ${ }^{2}$ College of Health Professions, Grand Valley State University, Allendale, Michigan; and ${ }^{3}$ Maternal Infant Health Program, Kent County Health Department, Grand Rapids, Michigan.

Address correspondence to: Carmen L. Nochera, Department of Biomedical Sciences, College of Liberal Arts and Sciences, Grand Valley State University, 1 Campus Drive, Allendale, MI 49401; e-mail: nocherac@gvsu.edu. fish oils, DHA can be derived from dietary $\alpha$-linolenic acid, although this conversion is inefficient. ${ }^{5}$ Dietary sources of $\alpha$-linolenic acid include flaxseed oil, canola oil, soybean oil, butternuts, and English walnuts. ${ }^{6}$

Developing fetuses depend on their mother's DHA stores for neuronal growth and maturation. The third trimester is the major period of DHA accumulation as the fetus' neurodevelopment is accelerated. ${ }^{7}$ During this period, DHA is used up rapidly by the unborn baby, and the pregnant woman's stores become depleted. ${ }^{8}$ As a result, pregnant and lactating women tend to be deficient in DHA. Unless these women consume at least 2 servings of fatty fish per week or supplement their diet with fish oils, their depleted stores of DHA could result in a deficiency for the infant, a situation that could have developmental consequences. ${ }^{9}$

Although there is no official Dietary Reference Intake (DRI) for DHA+EPA, the Institute of Medicine, the Food and Drug Administration and U.S. Environmental Protection Agency (FDA/EPA), the Institute of Medicine, the American Dietetic Association, Dietitians of Canada, 
and other organizations advise pregnant and lactating women to include 2 servings (up to $12 \mathrm{oz}$ ) of fish per week as a part of a balanced diet, ${ }^{10-12}$ which is equivalent to approximately $9 \mathrm{~g}$ of DHA+EPA per month or $300 \mathrm{mg}$ DHA+EPA daily. ${ }^{11}$ Unfortunately, there are a number of barriers to regular fish consumption. In noncoastal regions. fresh fish is not easily accessible, and the cost of fish is often higher than locally produced meats. Women with limited economic resources may be less inclined to purchase costly fish or fish oil supplements. Ethnic and cultural differences can influence fish consumption. Pregnant women may be advised by community health agencies and others to avoid mercury-contaminated fish, smoked seafood, and raw shellfish as well as fish caught from freshwater lakes and rivers that may be contaminated by heavy metals and PCBs. ${ }^{12}$ Pregnant and lactating women as well as women of childbearing age may not be well-informed about which fish are safe to eat, and thus women may choose to avoid eating any fish during pregnancy.

Relatively few studies have examined the relationship between DHA+EPA intake among pregnant and lactating women and demographic factors. The purpose of this study was to compare intake levels of DHA+EPA among low-income pregnant and lactating women to current guidelines. This population is at risk for low DHA+EPA consumption attributable to lack of education on the neurodevelopmental benefits of oily fish, limited financial resources, limited access to fish, and misinterpretation of the FDA/EPA advisory.

\section{Methods}

\section{Study Overview}

A cross-sectional, exploratory study was designed to assess the levels of DHA+EPA consumption among a sample population of low-income pregnant and lactating women. A 30-day diet recall questionnaire was used to estimate average monthly intake of DHA+EPA from food sources, to describe the sources of these $\omega-3$ fatty acids, and to determine whether any relationship existed between DHA+EPA intake and the following demographic factors: race and ethnicity (African American/ black, non-Hispanic Caucasian, Hispanic, or mixed), country of origin (United States other), primary language (English or other), level of education (less than high school, <9 years, some high school, high school diploma or GED, or some college), pregnant or lactating, marital status (yes or no), intake of prenatal vitamins (yes or no), and warnings of fish toxicity (yes or no) as determined from a demographic survey developed by the investigators. Average monthly consumption of fish, chicken, and turkey was converted to grams of DHA+EPA. Interpreters were used as requested by the participants. Each participant was interviewed 1 time. The data were collected September 2007 through March 2008. The study was approved by the Human Research Review Committee at Grand Valley State University, Grand Rapids, Michigan. Informed consent was obtained from each participant.

\section{Participants/Setting}

A convenience sample, one in which the patients are selected, in part or in whole, at the convenience of the researcher, was used for this study. A sample of 68 women was drawn from pregnant and lactating women enrolled in Maternal and Infant Health Program (MIHP), a program administered by the Kent County Health Department in Grand Rapids, Michigan. This organization is a locally and Medicaid-funded program that provides education and assistance to women of low socioeconomic status in Grand Rapids, Michigan. Women with fish and seafood allergies were excluded from the study.

\section{Food Frequency Questionnaire}

The tool used in the study was the N-3 Fatty Acid Food Frequency Questionnaire portion of the Diet Habit Survey. ${ }^{11}$ This 30 -day diet recall questionnaire was developed and used with permission by Sonja Connor, MS, $\mathrm{RD}$, and colleagues. ${ }^{13}$ This tool is currently a validated method of dietary assessment related to plasma cholesterol changes. Although this tool has not been validated for the assessment of DHA+EPA consumption, Arsenault and colleagues $^{14}$ found a strong correlation between DHA+EPA consumption estimated from a similar interviewer-administered Food Frequency Questionnaire and $\omega$-3 fatty acid content of plasma phospholipids. Average monthly consumption (ounces) of fish, chicken, and turkey was converted to grams of DHA+EPA using the Fatty Acid Food Frequency Questionnaire score sheet. ${ }^{13}$ The DHA+EPA content of chicken and turkey is considerably less than that of fish and seafood; for example, the DHA+EPA content of poultry is $0.01 \mathrm{~g} / \mathrm{oz}$ compared with $0.14 \mathrm{~g} / \mathrm{oz}$ for canned tuna, $0.21 \mathrm{~g} / \mathrm{oz}$ for catfish, $0.47 \mathrm{~g} / \mathrm{oz}$ for canned red salmon, and $0.62 \mathrm{~g} / \mathrm{oz}$ for sardines. ${ }^{13}$ The questionnaire was used to assess intake from food sources only. Thus, the DHA+EPA intakes presented in this study do not include intakes from supplements.

The recall questionnaire was administered by a registered dietitian employed by MIHP. The interviewer was trained by the investigators to ensure completion of the questionnaire by each participant. The questionnaire contained 32 questions and took approximately one-half hour to administer. The interviews took place either at the Kent County Health Department offices during routine check-ups or at the participant's home during home visits typically conducted upon enrollment into MIHP. 
Table 1. Average Monthly Consumption of DHA and EPA by Demographic Characteristics of Pregnant and Lactating Women

\begin{tabular}{|c|c|c|c|c|}
\hline Characteristics & No. & $\%$ & $\begin{array}{l}\text { Monthly Consumption of } \\
\text { DHA+EPA, g, Mean } \pm \mathrm{SE}^{\mathrm{b}}\end{array}$ & $P$ Value \\
\hline \multicolumn{5}{|l|}{ Ethnicity ${ }^{\mathrm{a}}$} \\
\hline African American/black & 18 & 26.5 & $2.79 \pm 0.51^{\mathrm{d}}$ & \\
\hline Caucasian & 7 & 10.3 & $0.93 \pm 0.36^{c}$ & \\
\hline Mixed race & 6 & 8.8 & $2.54 \pm 1.13^{\mathrm{c}, \mathrm{d}}$ & \\
\hline No & 38 & 55.9 & $1.55 \pm 0.24$ & \\
\hline Primary language $^{\mathrm{e}}$ & & & & .06 \\
\hline English & 29 & 42.6 & $2.40 \pm 0.43$ & \\
\hline Non-English & 39 & 57.4 & $1.60 \pm 0.24$ & \\
\hline Level of education ${ }^{\mathrm{a}}$ & & & & .62 \\
\hline Advised not to eat fish ${ }^{\mathrm{e}}$ & & & & .86 \\
\hline Yes & 19 & 28.8 & $1.86 \pm 0.42$ & \\
\hline No & 47 & 71.2 & $2.45 \pm 0.57$ & \\
\hline Pregnant/lactating ${ }^{\mathrm{e}}$ & & & & .77 \\
\hline Pregnant & 48 & 71.6 & $2.37 \pm 0.56$ & \\
\hline Lactating & 19 & 28.4 & $2.04 \pm 0.42$ & \\
\hline
\end{tabular}

DHA, docosahexaenoic acid; EPA, eicosapentaenoic acid; SE, standard error. Total sample size for each comparison did not always equal 68 because of missing data.

${ }^{a}$ Analysis of variance.

${ }^{b}$ Values followed by different letters are significantly different from one another; for example, ingestion of DHA+EPA by Hispanic participants is significantly different than that of African American participants but not significantly different than that of Caucasian participants.

${ }^{\mathrm{e}} t$ test.

\section{Statistical Analyses}

Descriptive statistics were calculated for the demographic characteristics of the participants. Quantitative demographic data were expressed as a mean plus or minus the standard error of mean. Nominal data were expressed as a percentage. The mean reported DHA+EPA consumption was compared between treatments using 2-tailed $t$ tests and 1-way analysis of variance. Multiple regression analyses were also run, with DHA+EPA consumption as the dependent variable. In one equation the independent variables were English speaking (yes or no), United States as country of origin (yes or no), and race (African American or other). In the second analysis the independent variables were English speaking (yes or no), United States as country of origin (yes or no), and ethnicity (Hispanic or other). $P$ values of .05 or less were considered statistically significant.

\section{Results}

\section{Descriptive Demographics}

The average age of all participants was $25.7 \pm 0.7$ years. Table 1 presents the self-reported ethnicities, level of education, country of origin, primary language, level of education, pregnancy/lactation status of the participants, and whether they had been advised to avoid eating fish. The reported country of origin of the participants is depicted in Table 2.

Results of the demographic analysis indicate that $64.2 \%$ of all the women in the study and $83.3 \%$ of the pregnant women were taking prenatal vitamins. Only 2 of the women, 1 pregnant and 1 breastfeeding, were taking prenatal vitamins that contained DHA. Among all women, both pregnant and lactating, only 1 took additional supplements of fish oil or flaxseed oil that contained DHA. 
Table 2. Country of Origin of Participants

\begin{tabular}{lcc}
\hline Country of Origin & Frequency & $\%$ \\
\hline United States & 30 & 44.1 \\
Mexico & 22 & 32.4 \\
Guatemala & 6 & 8.8 \\
El Salvador & 3 & 4.4 \\
Other $^{\mathrm{a}}$ & 6 & 9.0 \\
\hline
\end{tabular}

${ }^{a}$ One participant each from Burundi, Canada, Puerto Rico, Sierra Leone, Somalia, and Sudan.

This additional DHA was not included in the data analysis because the quantity of DHA in the supplement was unknown. Almost a third of the women studied (28.8\%) were advised not to eat fish during their prenatal visit, most often by their doctor, a dietitian, or a representative from WIC. Other women described receiving this advice from a friend, nurse, or mother.

\section{DHA+EPA Consumption}

The average DHA+EPA consumption for all women studied was $1.18 \mathrm{~g} \pm 0.41$ monthly. This is $13 \%$ of the advisable intake of $9 \mathrm{~g} /$ month. ${ }^{11}$ Results indicate that both race/ethnicity and country of origin are related to total DHA + EPA intake. There were no significant relationships between the remaining demographic factors and average consumption of DHA+EPA $(P>.05)$ (Table 1$)$.

The monthly intake of DHA+EPA was greatest among African American/black women, with a monthly average of $31 \%$ of the advisable intake of $9 \mathrm{~g}$. This was followed by women of mixed racial ethnicity, Hispanic women, and non-Hispanic Caucasian women (Table 1). The mean amount of DHA+EPA consumed by African American/ black women per month was significantly higher than the amount consumed monthly by Hispanic women and by non-Hispanic Caucasian women $(P<.05)$ (Table 1$)$.

The country of origin was compared with DHA+EPA intake. Individuals born in the United States consumed more DHA+EPA on average per month compared with nonnative immigrants $(P<.05)$ (Table 1$)$.

Because of the interrelated nature of some of the variables, multiple regression analyses were also run with DHA+EPA consumption as a dependent variable. In the first analysis, using English speaking, U.S. native (yes or no), and race (African American or other) as the independent variables, the regression model was not significant, with $P=.08$. The variable that came closest to being a predictor was race, with $P=.08$. In the second model, the only difference was defining race as Hispanic or other. Once again, the regression model was not significant, with $P=.29$. The variable that came closest to being a predictor was U.S. native, with $P=.38$.

\section{Discussion}

The neurological benefits of DHA and EPA have been well established for developing infants. ${ }^{3,15-17}$ Consumption of 1-2 servings of fatty fish per week or approximately $9 \mathrm{~g}$ of DHA+EPA per month by pregnant and lactating women provides their growing infants with sufficient quantities to receive these benefits. ${ }^{16}$ Pregnant women of low socioeconomic status are at risk for DHA deficiency because of limited access to fish or fish oil supplements. ${ }^{18,19}$

The women in this study consumed less than the recommended 1-2 fatty fish meals per week or $9 \mathrm{~g}$ of DHA+EPA per month. The average DHA+EPA consumption among all the women studied was only $13 \%$ of the advisable intake. In fact, none of the 68 pregnant and/or lactating women in the study consumed the recommended amounts of $\omega-3$ fatty acids. This low $\omega-3$ fatty acid consumption rate is consistent with findings of previous studies. ${ }^{18-21}$ These data provide additional evidence that pregnant and lactating women of low socioeconomic status are at risk for DHA+ EPA deficiency.

Troxell et $\mathrm{al}^{20}$ reported that an important barrier to DHA+EPA consumption is the cost of DHA- and EPArich foods. This may be true in the current study. For example, fresh fish such as salmon, sardines, herring, and orange roughy contain greater than $0.3 \mathrm{~g}$ of DHA+EPA per serving $(6 \mathrm{oz})$ but are more costly than the sources of DHA and EPA most commonly reported in the survey. Only $4.5 \%$ of participants ate fresh or frozen salmon, and even fewer women ate sardines, herring, or orange roughy. The high cost of fresh fish may therefore affect food choices of the women in the study.

The data indicate that DHA+EPA consumption is higher among African American/black women than that of other ethnic groups. There are several reasons why race and ethnicity can influence fish and seafood consumption. Cultural food traditions may play a large role. In addition, women reared in regions with access to fish and whose diets have traditionally contained greater quantities of fish may be more likely to maintain a higher level fish intake despite relocation to an area with less availability or greater cost of fish.

Country of origin was also found to be related to fish consumption. According to the data, women from the United States ate an average of $2.45 \mathrm{~g}$ of DHA+EPA in a month, $27 \%$ of the advised amount. Women from other countries ate significantly less fish $(P<.05)$, an average of $1.55 \mathrm{~g}$ of DHA+EPA in a month, $17 \%$ of advised amount.

The difference in fish consumption between U.S. natives and immigrants in this study may reflect the availability of fish in the given countries of origin. The United 
States imports fish from many other countries. It is possible that U.S. citizens enjoy a greater availability of fish than citizens of the other countries represented in this study, such as Mexico, Guatemala, El Salvador, Somalia, and Sudan.

Race/ethnicity, country of origin, and primary language are 3 factors that are closely related to DHA+EPA consumption and closely related to each other within this sample. Multiple regression analyses were performed to see whether DHA+EPA can be predicted using these 3 factors. There was not sufficient evidence that any of these factors affected DHA+EPA intake (race/ethnicity, $P=.08$; country of origin, $P=.29$; primary language, $P=.39$ ).

Although not significant, the level of education was related to fish consumption. Women with higher levels of education tended to eat more fish than those with less than a high school education (Table 1). However, educational level is closely related to socioeconomic status. More specifically, women with less than a high school education are more likely to live in poverty. ${ }^{22}$ Given that previous studies have shown that women in poverty are less likely to eat fish because of cost, it follows that women with lower educational levels and lower income are at risk for deficiencies of DHA/EPA. ${ }^{19}$

No significant relationship was discovered between DHA+EPA consumption and marital status, pregnancy/ lactation status, and advisory of fish toxicity. Previous studies indicate ${ }^{13,23,24}$ that women who have received warnings of fish toxicity consume less fish. The data from this study revealed that $29 \%$ of the women had been warned to avoid certain fish or seafood during pregnancy or while breastfeeding. However, there was no significant difference in the consumption of fish in these women compared with women who had not been advised to avoid fish. Women were consuming equally low quantities of fish, regardless of the EPA/FDA advisory.

There were several limitations in this study. First, the use of a 30-day dietary recall survey relies on the memory of the participants being surveyed. Because participants were asked to recall their consumption of fish from the previous month instead of keeping a continuous food journal over a period of time, the estimates of their eating habits may be inaccurate; however, this is an inherent limitation in dietary recall methods. ${ }^{25}$ Second, the use of convenience sampling of participants limits the generalizability of the results. Third, the variation in primary language and use of interpreters may also present a possible source of error. For example, 57\% of participants listed a language other than English as their primary language. and $44 \%$ of participants requested the use of an interpreter. Different interpreters were used with different participants. Thus, validity may be reduced because of differences in interviewing style and language during the interview process.
The omission of "other" fish eaten from DHA+EPA calculations for a number of participants is an additional limitation to this study. Some women did not know what type of fish they ate, and others described eating fish whose DHA+EPA content was unknown; thus, numbers in this category were not included in the DHA+EPA totals. Furthermore, the additional DHA consumption of the 3 participants taking supplements containing DHA were not included in the DHA+EPA totals, because the food frequency questionnaire was developed to include only food sources of DHA+EPA. As a result, the average intake of DHA+EPA for some women is higher than the recorded values.

\section{Conclusion}

Although there is no universal agreement on DHA+EPA intake, this study provides evidence that pregnant and lactating women of low socioeconomic status are at risk for low intake of $\omega-3$ fatty acid. Clarification of the DHA+EPA content of "other" fish eaten will provide more information about the DHA+EPA intake of this group of women. Factors such as race/ethnicity and country of origin are associated with lower than advisable intake levels of DHA+EPA consumption in this study. Additional studies with larger sample sizes are recommended to further delineate these barriers to DHA+EPA consumption.

It is incumbent on healthcare practitioners to advise pregnant and lactating women of the advisable intake, which can be can be achieved by eating 1-2 oily fish meals per week. In addition, these practitioners must be made aware of the types of fish that can be safely eaten if they are recommending that pregnant or lactating women avoid eating fish contaminated with heavy metals. Safe sources of $\omega-3$ fatty acids that may be accessible to lowincome women include canned tuna and catfish.

Pregnant and lactating women, regardless of socioeconomic status, should aim to achieve the advisable dietary intake of DHA+EPA. As the factors associated with inadequate intake of DHA+EPA become more clearly defined, educational intervention programs promoting DHA+EPA awareness and consumption should be developed that target the groups most clearly at risk. Once these programs are established and implemented, further studies examining their effectiveness are recommended.

\section{References}

1. Wainwright PE. Dietary essential fatty acids and brain function: a developmental perspective on mechanisms. Proc Nutr Soc. 2002;61:61-70.

2. Auestad N, Scott D, Janowsky J, et al. Visual, cognitive, and language assessments at 39 months: a follow-up study of children fed 
formulas containing long-chain polyunsaturated fatty acids to 1 year of age. Pediatrics. 2003;112:e177-e183.

3. Helland IB, Saugstad OD, Smith L, et al. Similar effects on infants of n-3 and n-6 fatty acids supplementation to pregnant and lactating women. Pediatrics. 2001;108:e82-e92.

4. Cheruku SR, Montgomery-Downs HE, Farkas SL, Thoman EB, Lammi-Keefe CJ. Higher maternal plasma docosahexaenoic acid during pregnancy is associated with more mature neonatal sleepstate patterning. Am J Clin Nutr. 2002;76:608-613.

5. Innis SM, Friesen RW. Essential n-3 fatty acids in pregnant women and early visual acuity maturation in term infants. Am J Clin Nutr. 2008;87:548-557.

6. Flax Council of Canada. Food sources of alpha-linolenic acid (ALA). 2006. http://www.gvflax.com/articles/alpha_linolenic.htm. Accessed May 11, 2010.

7. Colombo J, Kannass KN, Shaddy DJ, et al. Maternal DHA and the development of attention in infancy and toddlerhood. Child Dev. 2004;75:1254-1267.

8. Makrides M, Neuman M, Simmer K, Pater J, Gibson R. Are longchain polyunsaturated fatty acids essential nutrients in infancy? Lancet. 1995;345:1463-1468.

9. Oh R. Practical applications of fish oil (omega-3 fatty acids) in primary care. J Am Board Fam Pract. 2005; 18:28-36.

10. What you need to know about mercury in fish and shellfish. US Environmental Protection Agency Web site. http://www.cfsan.fda. gov/ dms/admehg3.html. Accessed March 17, 2009.

11. Kris-Etherton PM, Grieger JA, Etherton TD. Dietary reference intakes for DHA and EPA. Prostaglandins Leukot Essent Fatty Acids. 2009;81:99-104.

12. Food and Nutrition Board. Seafood choices: balancing benefits and risks. Institute of Medicine Web site. October 13, 2006. http:// www.iom.edu/Reports/2006/Seafood-Choices-Balancing-Benefitsand-Risks.aspx. Last update October 11, 2009. Accessed January 14, 2011.

13. Connor SL, Gustafson JR, Sexton GS, Becker N, Artaud-Wild S, Connor WE. The diet habit survey: a new method of dietary assessment that relates to plasma cholesterol changes. J Am Diet Assoc. 1992;92:41-47.

14. Arsenault LN, Matthan N, Scott TM, et al. Validity of estimated dietary eicosapentaenoic acid and docosahexaenoic acid intakes determined by interviewer-administered food frequency questionnaire among older adults with mild-to-moderate cognitive impairment or dementia. Am J Epidemiol. 2009;170:95-103.

15. Hoffman DR, Theuer RC, Castaneda YS, Wheaton DH. Maturation of visual acuity is accelerated in breast-fed term infants fed baby food containing DHA-enriched egg yolk. J Nutr. 2004;134: 2307-2313.

16. McCann JC, Ames BN. Is docosahexaenoic acid, an n-3 long-chain polyunsaturated fatty acid, required for development of normal brain function? Am J Clin Nutr. 2005;82:281-295.

17. Helland IB, Smith L, Saarem K. Maternal supplementation with very long-chain $\mathrm{n}-3$ fatty acids during pregnancy and lactation augments children's IQ at 4 years of age. Pediatrics. 2003;111:e39-e44.

18. Loosenmore ED, Judge MP, Lammi-Keefe CJ. Dietary intake of essential and long-chain polyunsaturated fatty acids in pregnancy. Lipids. 2004;39:42 1-424.

19. Denomme J, Stark KD, Holub BJ. Directly quantitated dietary (n-3) fatty acid intakes of pregnant Canadian women are lower than current dietary recommendations. J Nutr. 2005;135:206-211.

20. Troxell H, Anderson J, Auld G, et al. Omega-3 for baby and me: material development for a WIC intervention to increase DHA intake during pregnancy. Maternal Child Health J. 2005;9: 189-197.

21. Valentine CJ, Morrow G, Fernandez S, et al. Docosahexaenoic acid and amino acid contents in pasteurized donor milk are low for preterm infants. J Pediatr. 2010;157:906-910.

22. US Department of Commerce, Economics, and Statistics Administration. US Census Bureau Web site. 2003. http://www .census.gov/prod/2003pubs /c2kbr-24.pdf. Accessed April 16, 2008.

23. Oken E, Kleinman KP, Berland W, Simon SR, Rich-Edwards JW, Gillman M. Decline in fish consumption among pregnant women after a national mercury advisory. Obstet Gynecol. 2003;102: 346-351.

24. Vardeman JE, Aldoory L. A qualitative study on how women make meaning of contradictory media messages about the risks of eating fish. Health Commun. 2008;23:282-291.

25. Harrison GG, Galal OM, Ibrahim N, et al. Underreporting of food intake by dietary recall is not universal: a comparison of data from Egyptian and American women. J Nutr. 2000;130: 2049-2054. 